\title{
Left circumflex artery supplying the territory of right coronary artery: an extremely rare variant of a congenital single coronary artery
}

\author{
Davinder Pal Singh, ${ }^{1}$ Kunal Mahajan, ${ }^{1}$ Prakash Negi, ${ }^{1}$ Bavneet Kour Bali ${ }^{2}$
}

'Department of Cardiology, Indira Gandhi Medical College, Shimla, Himachal Pradesh, India

${ }^{2}$ Department of Pathology, Government Medical College Jammu, Jammu and Kashmir, India

\section{Correspondence to}

Dr Kunal Mahajan, kunalmahajan442@gmail.com

Accepted 8 March 2016
CrossMark

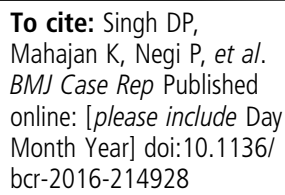

\section{DESCRIPTION}

A 68-year-old woman presented with exertional retrosternal chest pain with radiation to the left arm, of 1-week duration. Medical history revealed a history of bronchial asthma. Family history was negative for heart disease. The patient's blood pressure was $138 / 80 \mathrm{~mm} \mathrm{Hg}$ and her heart rate was $68 \mathrm{bpm}$. Cardiovascular and chest examination were unremarkable. A resting electrocardiogram displayed normal sinus rhythm without any ST-segment abnormalities. Transthoracic echocardiography demonstrated normal biventricular function and normal regional wall motion. Treadmill test was positive for inducible ischaemia at low workload. Laboratory testing was unremarkable. Coronary angiography showed a left anterior descending coronary artery (LAD) arising normally from the left coronary sinus with diffuse proximal and mid-LAD calcific disease with maximum $80 \%$ stenosis (figure 1). The left circumflex artery (LCX) was the dominant vessel with its terminal branch supplying the territory of the right coronary artery (RCA) (figures 2 and 3). We failed to cannulate the RCA ostium, therefore aortic root angiography was performed to exclude an atypical take-off of the RCA. However, the RCA was not visualised on aortic root angiography (figure 4). This case thus described an extremely rare anomaly of a congenital single coronary artery (SCA) with RCA arising from a terminal extension of the LCX. The patient was managed with rota-ablation using percutaneous

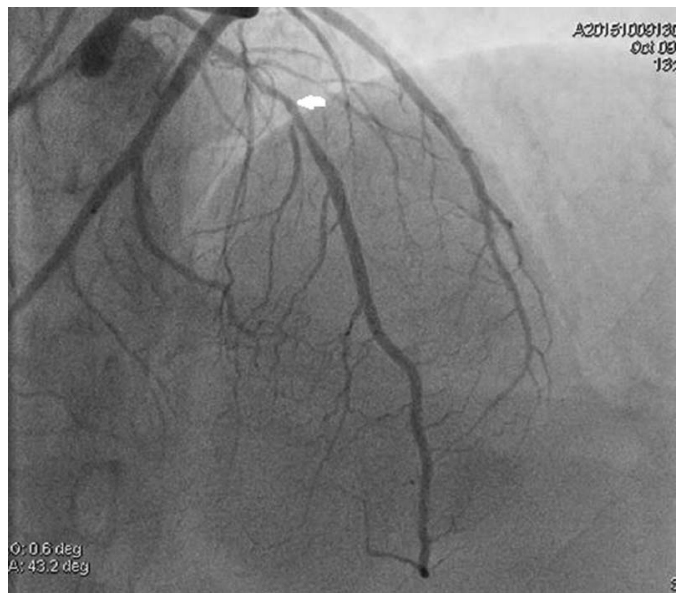

Figure 1 Left coronary artery angiogram showing a normally arising LAD with a significant lesion in mid-LAD (arrow). LAD, left anterior descending.

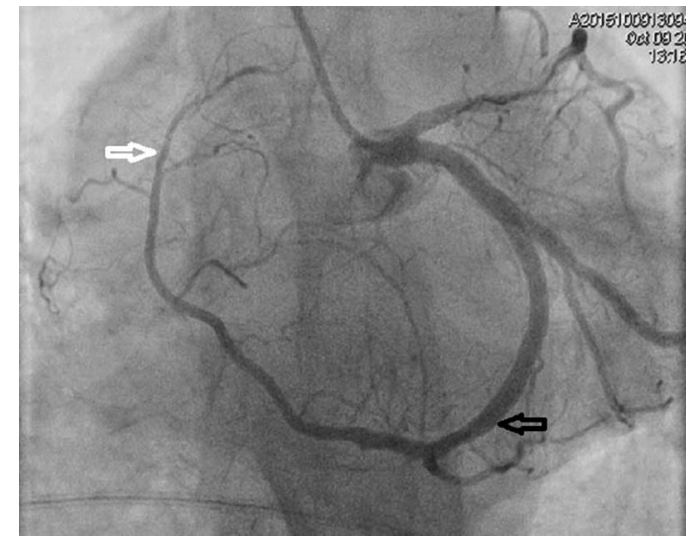

Figure 2 Left coronary artery angiogram, AP caudal view, showing RCA territory (white arrow) supplied by terminal extension of LCX (black arrow). AP, anteroposterior; LCX, left circumflex artery; RCA, right coronary artery.

coronary transluminal angioplasty and stenting of the LAD. She was relieved of angina postprocedure. A SCA is an extremely rare congenital anomaly with an incidence of only $0.024 \%$ to $0.066 \%$ in the general population. ${ }^{1}$ The clinical significance of SCAs is not clear and it is generally considered to be benign. However, there are reports suggesting its association with cardiac ischaemia, cardiomyopathy, sudden cardiac death and congestive heart failure, even in the absence of atherosclerosis. ${ }^{2} 3$

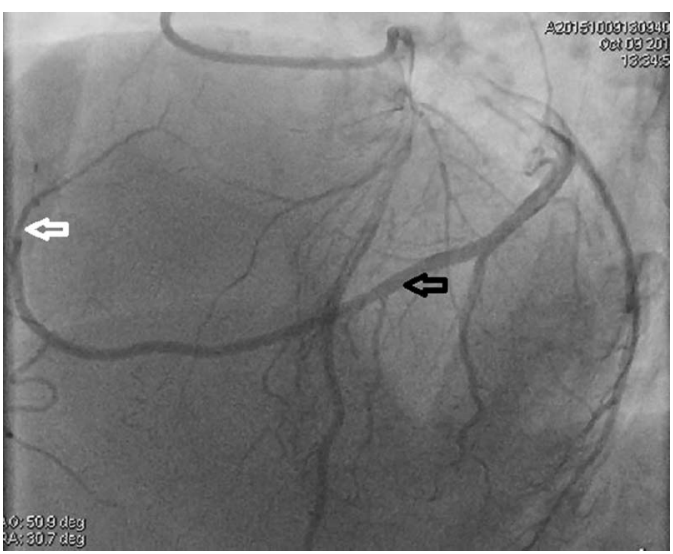

Figure 3 Left coronary artery angiogram, LAO cranial view, showing distal LCX (black arrow) continuing as RCA (white arrow). LAO, left anterior oblique; LCX, left circumflex artery; RCA, right coronary artery. 
Figure 4 Non-selective injection in the right coronary sinus $(A)$ and non-coronary sinus (B). Note that the RCA is not visualised. However, the left coronary artery is seen arising from the left coronary sinus (arrow), establishing the diagnosis of a single coronary artery. RCA, right coronary artery.

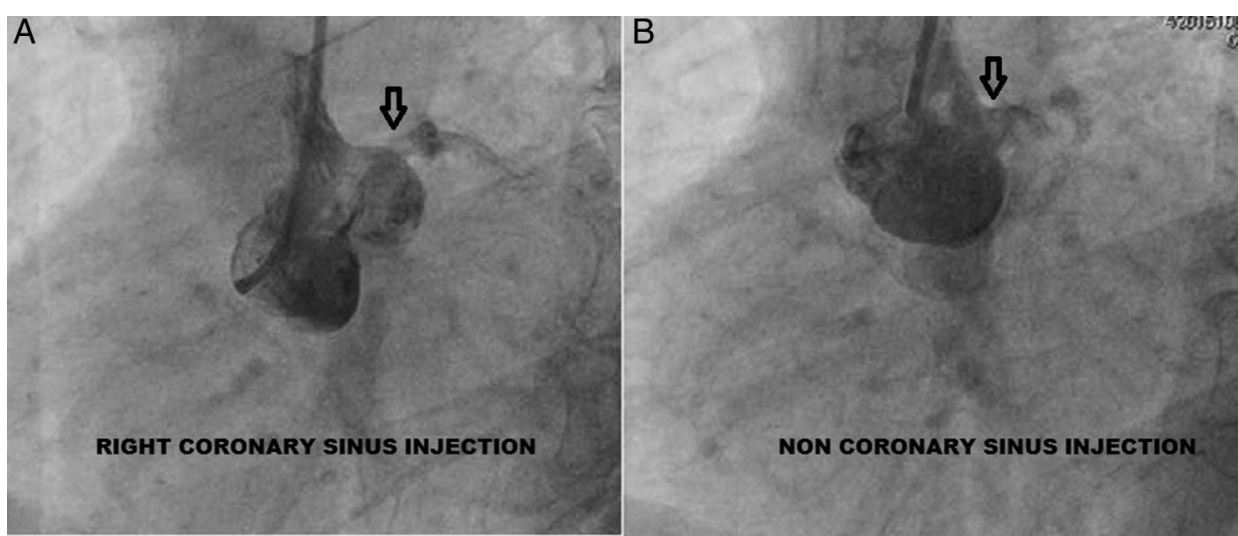

Competing interests None declared.

Patient consent Obtained.

Provenance and peer review Not commissioned; externally peer reviewed.

\section{REFERENCES}

1 Lipton MJ, Barry WH, Obrez I, et al. Isolated single coronary artery: diagnosis, angiographic classification, and clinical significance. Radiology 1979;130:39-47.

2 Ohshima T, Lin Z, Sato Y. Unexpected sudden death of a 12-year-old male with congenital single coronary artery. Forensic Sci Int 1996;82:177-81.

3 Chung SK, Lee SJ, Park SH, et al. An extremely rare variety of anomalous coronary artery: right coronary artery originating from the distal left circumflex artery. Korean Circ J 2010;40:465-7.

Copyright 2016 BMJ Publishing Group. All rights reserved. For permission to reuse any of this content visit http://group.bmi.com/group/rights-licensing/permissions.

BMJ Case Report Fellows may re-use this article for personal use and teaching without any further permission.

Become a Fellow of BMJ Case Reports today and you can:

- Submit as many cases as you like

- Enjoy fast sympathetic peer review and rapid publication of accepted articles

- Access all the published articles

- Re-use any of the published material for personal use and teaching without further permission

For information on Institutional Fellowships contact consortiasales@bmjgroup.com

Visit casereports.bmj.com for more articles like this and to become a Fellow 